\title{
O impacto do coronavírus (covid-19) na prática odontológica: desafios e métodos de prevenção
}

\author{
The impact of coronavirus (covid-19) on dental practice: challenges and prevention \\ methods \\ El impacto del coronavirus (covid-19) en la práctica dental: desafíos y métodos de \\ prevención
}

José Jhenikártery Maia de Oliveira ${ }^{1 *}$, Karolyne de Melo Soares ${ }^{2}$, Kauana da Silva Andrade ${ }^{1}$, Micaella Fernandes Farias ${ }^{1}$, Thaynara Cavalcante Moreira Romão ${ }^{1}$, Rachel Christina de Queiroz Pinheiro ${ }^{1}$, Artemisa Fernanda Moura Ferreira ${ }^{1}$, Fernanda de Araújo Trigueiro Campos ${ }^{1}$.

\section{RESUMO}

Objetivo: Descrever o impacto do COVID-19 na prática odontológica mediante os métodos de prevenção adotados aos desafios decorrentes da fácil transmissibilidade viral. Métodos: Trata-se de uma revisão de literatura, onde foram utilizados artigos nacionais e internacionais publicados nos últimos três meses (janeiromarço de 2020), indexados em duas bases de dados: PubMed e MEDLINE. Para seleção dos artigos utilizouse os descritores "Coronavírus (Coronavirus)" and "Prática Odontológica (Dental Practice)", resultando em uma amostra de $(n=5)$ artigos para leitura completa. Resultados: Os profissionais da Odontologia se enquadram em grupos de grande exposição ao Covid-19, considerando que o ambiente odontológico favorece a infecção cruzada permitindo um maior índice de contágio viral, devido a uma comunicação face a face, exposição a aerossóis compostos de saliva, sangue e outros fluidos. Protocolos rigorosos e eficientes são necessários para o controle da transmissão. Para tanto, os profissionais da Odontologia necessitam possuir conhecimento sobre os requisitos de prevenção e controle do Covid-19. Considerações finais: Os cirurgiõesdentistas desempenham importante papel no controle e prevenção do Covid-19, dessa forma, durante a pandemia deve-se priorizar os atendimentos de urgência, além de reforçar as medidas de biossegurança e anamnese detalhada em busca dos sintomas da doença.

Palavras-chave: Coronavírus, Odontologia, Controle de infecções.

\begin{abstract}
Objective: To describe the impact of COVID-19 on dental practice using the prevention methods adopted in the challenges of easy viral transmission. Methods: This is a literature review, where national and international articles published in the last three months (January-March 2020) were published, indexed in two databases: PubMed and MEDLINE. For the selection of articles used, the descriptors "Coronavirus (Coronavirus)" and "Prática Odontológica (Dental Practice)", result in a sample of $(n=5)$ articles for complete reading. Results: Dentistry professionals fall into groups with high exposure to Covid-19, considering that the dental environment favors cross-infection, allowing a higher rate of viral contagion, due to face-to-face communication, exposure to saliva-containing aerosols, blood and other fluids. Strict and efficient protocols are able to control transmission. For dental professionals who have knowledge about the requirements of control control and Covid-19. Final considerations: Dental surgeons play an important role in the control and prevention of Covid-19, thus, during a pandemic before prioritizing urgent activities, in addition to reinforcing the biosafety and anamnesis measures evaluated in search of the symptoms of the disease.
\end{abstract}

Key words: Coronavírus, Dentistry, Infection control.

${ }^{1}$ Centro Universitário de João Pessoa (UNIPÊ), João Pessoa - PB. *E-mail: jhenikarterymaia@gmail.com

2 Centro Universitário Uniesp (UNIESP), Cabedelo - PB. 


\section{RESUMEN}

Objetivo: describir el impacto de COVID-19 en la práctica dental utilizando los métodos de prevención adoptados en los desafíos de la transmisión viral fácil. Métodos: Esta es una revisión de la literatura, donde se publicaron artículos nacionales e internacionales publicados en los últimos tres meses (enero-marzo de 2020), indexados en dos bases de datos: PubMed y MEDLINE. Para la selección de los artículos utilizados, los descriptores "Coronavirus (Coronavirus)" y "Dental Practice (Dental Practice)" dan como resultado una muestra de $(n=5)$ artículos para una lectura completa. Resultados: los profesionales de la odontología se dividen en grupos con alta exposición a Covid-19, ya que el entorno dental favorece la infección cruzada, lo que permite una mayor tasa de contagio viral, debido a la comunicación cara a cara, la exposición a aerosoles compuestos de saliva, sangre y otros fluidos. Los protocolos estrictos y eficientes pueden controlar la transmisión. Para profesionales dentales que tienen conocimiento sobre los requisitos de control de control y Covid-19. Consideraciones finales: los cirujanos dentales juegan un papel importante en el control y la prevención de Covid-19, por lo tanto, durante una pandemia antes de priorizar actividades urgentes, además de reforzar las medidas de bioseguridad y anamnesis evaluadas en busca de los síntomas de la enfermedad.

Palabras clave: Coronavírus, Odontología, Control de Infecciones.

\section{INTRODUÇÃO}

Pandemias são caracterizadas como doenças infecciosas que tomam proporção por grandes áreas geográficas, espalhando-se rapidamente ao redor do mundo e ao mesmo tempo. Algumas pandemias significativas já ocorridas foram a gripe ( $\mathrm{H} 1 \mathrm{~N} 1$ e espanhola), cólera, varíola e, em dezembro de 2019, uma nova pneumonia denominada Corona Vírus Disease 19 (Covid-19), tornou-se emergência de saúde pública (TUÑAS ITC, et al., 2020; XU H, et al., 2020). Os Coronavírus pertencem à família de vírus denominada Coronaviridae e são nomeados dessa forma por apresentarem espículas/peplômeros que formam uma estrutura semelhante a uma coroa.

Quanto à essa espécie de vírus, sete são reconhecidos como patógenos capazes de infectar os humanos como o 229E e o OC43, que em 1960, causaram um leve resfriado, enquanto, em 2003, foi descoberto o SARS-CoV, o causador da síndrome respiratória aguda grave. Nos anos subsequentes, 2004 e 2005, os tipos HCoV - NL63 e HKU-1, respectivamente, promoveram complicações respiratórias como a bronquiolite, que é o bloqueio dos bronquíolos dos pulmões causado por uma infecção viral. Em 2012 foi identificado o MERSCoV, que causa a síndrome respiratória do oriente médio (CORMAN VM, et al., 2019; GUO YR, et al., 2020; WANG HJ, et al., 2020). Em 2012, o MERS-CoV causou complicações graves no sistema respiratório dos infectados, pneumonia grave e ainda complicações renais, o qual resultou em altos índices de mortalidade (em torno de 20 a 40\%), enquanto em 2019, foi descoberto o sétimo patógeno, o SARS-CoV-2, um novo coronavírus humano, denominado de Síndrome Respiratória Aguda Grave Coronavírus 2, causador do Covid19.

O primeiro caso de Covid-19 reportado pela OMS (Organização Mundial da Saúde) aconteceu em Wuhan, capital da China central, disseminando-se pelos demais continentes (PEERI NC, et al., 2020; DOREMALEN N, et al., 2020; ORGANIZAÇÃO MUNDIAL DA SAÚDE, 2020). Atualmente sabe-se que a origem do vírus estava associada ao Mercado Atacadista de Frutos do Mar de Huanan e de acordo com o sequenciamento do genoma do SARS-CoV-2, o morcego foi identificado como hospedeiro natural do vírus, que infecta humanos por meio de hospedeiros intermediários.

Por consequência, o surto epidêmico iniciou-se na transmissão entre humanos. Os sinais e sintomas decorrentes da infecção variam de leve a grave, podendo se apresentar de forma subclínica em alguns indivíduos que por desconhecer a atual condição de saúde, disseminam o vírus, e representam um alto risco para populações vulneráveis que estão mais susceptíveis às complicações por Covid-19 (MUNSTER VJ, et al., 2020; GUO YR, et al., 2020; LI Q, et al., 2020). 
As principais vias de transmissão do Covid-19 incluem a tosse, espirro, gotículas contaminadas, contato com mucosa oral, nasal e olhos, podendo também ser transmitido de pessoa para pessoa através de saliva e fluidos. Os principais sintomas iniciam, geralmente, após uma semana e consistem em congestão nasal, tosse, febre e fadiga. A pneumonia tende a aparecer na segunda ou terceira semana de infecção, já a letalidade relacionada ao Covid-19, até o momento, tem sido predominantemente associada a pacientes com presença de comorbidades, tais como doenças cardiovasculares, hipertensão arterial e diabetes mellitus, que afetam o sistema imunológico e idosos. O período de incubação, embora ainda não esteja bem estabelecido, varia de 4 a 14 dias. Por ter sido catalogada recentemente, o comportamento do vírus não foi completamente estudado, tendo atualmente dados preliminares que precisam de uma melhor investigação. (VELAVAN TP; MEYER CG, 2020; LANA RM, et al., 2020; STRABELLI TMV; UIP DE, 2020).

Atualmente não há medidas farmacológicas disponíveis e cientificamente comprovadas para o tratamento, que sejam eficazes no controle da doença, dessa forma, a Organização Mundial de Saúde recomenda medidas de isolamento social a fim de manter a propagação do vírus sob controle (MARCEL S, et al., 2020).

Durante o atendimento, os Cirurgiões-Dentistas (CDs) estão em constante exposição a fluídos corporais como saliva e sangue, além de produtos resultantes de aerossóis e instrumentos cortantes que foram contaminados durante seu uso. Dessa forma, as condutas em biossegurança tornam-se, ainda mais, necessárias para a proteção do profissional e do paciente, evitando-se infecções cruzadas. (CAMPOS TUÑAS, et al., 2020; YANG Y, et al., 2020).

Diante disso, esta pesquisa bibliográfica teve como objetivo descrever o impacto do Covid-19 na prática odontológica mediante os métodos de prevenção adotados aos desafios decorrentes da fácil transmissibilidade viral.

\section{MÉTODOS}

Trata-se de um estudo de revisão de literatura, acerca do impacto do Covid-19 na prática odontológica. A pesquisa bibliográfica abrange uma busca sistematizada de artigos originais publicados nas bases de dados PubMed (National Library of Medicine, USA - NLM) e MEDLINE (Medical Literature Analysis and Retrieval System Online), sobre o tema em questão. Para realização da revisão foram utilizadas as palavras-chave em português e inglês, respectivamente: "Coronavírus (Coronavirus)" and "Prática Odontológica (Dental Practice)".

Os critérios de inclusão utilizados foram: artigos nacionais e internacionais publicados nas bases de dados já citadas publicados nos últimos três meses (janeiro-março de 2020), que estivessem relacionados com o tema proposto, atendendo aos objetivos do trabalho. Após a consulta das palavras-chave supracitados, 18 artigos foram identificados e escolhidos para leitura completa; dentre esses, 13 artigos foram excluídos do estudo, pois não apresentavam relação com o tema proposto e não atendiam os critérios de inclusão, resultando um total de 5 artigos selecionados para compor a amostra (Figura 1). 
Figura 1 - Fluxograma ilustrativo da seleção dos artigos.

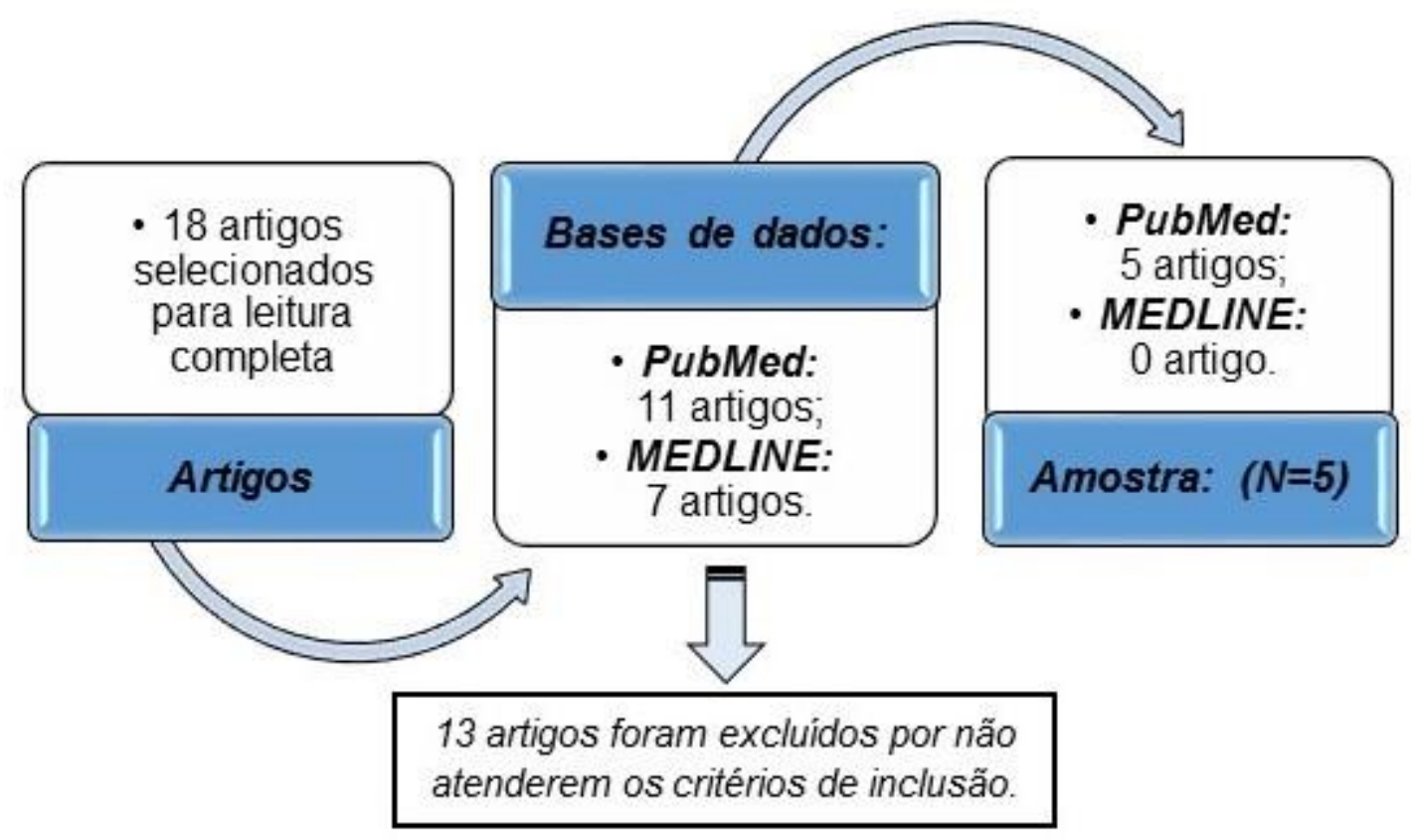

Fonte: Oliveira JJM, et al., 2020

Os dados foram organizados em uma planilha de Excel de acordo com as seguintes informações dos estudos selecionados: autores, ano, local de realização dos estudos, objetivo, resultados e conclusão.

\section{RESULTADOS}

Na prática odontológica, o risco de infecção cruzada é potencializado entre os Cirurgiões-Dentistas (CDs) e os pacientes devido ao modo de transmissão da infecção que ocorre por meio do contato direto com as gotículas respiratórias do paciente infectado. Dessa forma, especula-se que o CD seja mais vulnerável ao contágio pelo uso de aerossóis no consultório, ainda que não haja evidência científica que suporte esta informação (MENG L, et al., 2020).

Associado a isso, apenas pacientes com sintomatologia eram considerados potenciais fontes de transmissão do vírus, no entanto, observa-se que os indivíduos assintomáticos, no período de incubação, fase compreendida entre a exposição ao patógeno e o aparecimento dos primeiros sinais e sintomas da doença, ao qual pode durar até 14 dias, podem ser agentes de transmissão do vírus (MENG L, et al., 2020).

Meng L, et al. (2020) reforçam que a maioria dos procedimentos odontológicos envolvem a produção de um grande número de gotículas e aerossóis, dessa forma, as medidas de biossegurança preconizadas na atuação clínica do CD não são eficientes para impedir a disseminação do Covid-19 principalmente, nos casos em que os pacientes estão assintomáticos.

Diante disso, ainda não existe um consenso em relação às orientações sobre a prestação de serviços odontológicos durante a pandemia do Covid-19, mas, como mecanismo de prevenção e controle da infecção, é preconizado que os dentistas reforcem as medidas de segurança através dos equipamentos de proteção individual (EPIs) e, evitem, quando possível, a realização de procedimentos que envolvam a produção de aerossóis e de gotículas.

Devido ao crescente número de casos de Covid-19 no Brasil, os CDs devem estar aptos na identificação dos pacientes com sinais e sintomas da infecção e então adotarem condutas preventivas na prática clínica, seguindo rigorosamente as medidas de biossegurança em todos os atendimentos odontológicos, independente se há suspeita ou não da contaminação pelo Covid-19, mesmo que não impeça a disseminação. 
A propagação por meio de superfícies contaminadas, considerando as gotículas e aerossóis gerados no atendimento, ocasiona a contaminação de superfícies nos consultórios odontológicos e consideram que a manutenção de um ambiente limpo e seco ajuda a diminuir a resistência do vírus.

Com base nas diretrizes da Comissão Nacional de Saúde da República Popular da China, autores sugerem medidas a fim de controlar a disseminação do Covid-19; a identificação de pacientes com sintomas é uma atitude crucial antes do atendimento.

As demais medidas baseiam-se na higienização das mãos; uso de equipamentos de proteção individual; uso de enxaguatório bucal antes do procedimento, optando por agentes de oxidação a $1 \%$ ou povidona a 0,2\%; uso de isolamento absoluto; não utilização de peças de mão sem a função de alta-rotação, visto que estas podem aspirar e expelir fluídos aumentando o risco de infecção cruzada; desinfecção do ambiente (PENG X, et al., 2020).

Estudos sugerem que o SARS-CoV-2 possui predisposição a ligação celular com receptores específicos, a principal consiste na enzima conversora de angiotensina 2 (ACE2).

Sendo assim, as células que expressam o ACE2 desempenham um papel fundamental, pois atuam como célula alvo. Com a investigação da via potencial de infecção pelo Covid-19 na mucosa da cavidade oral, os autores sustentam que entre os diferentes locais da cavidade bucal, a lingual obteve a maior expressão de ACE2, dessa forma, a cavidade oral é considerada uma via de alto risco para a infecção (XU H, et al., 2020).

O Quadro 1 mostra os principais resultados encontrados nos artigos selecionados para a amostra do presente estudo: 
Quadro 1 - Descrição dos dados encontrados nos artigos incluídos.

\begin{tabular}{|c|c|c|c|c|c|c|}
\hline & Autor & Ano & $\begin{array}{l}\text { Local do } \\
\text { estudo }\end{array}$ & Objetivo & Resultados & Conclusão \\
\hline 1 & $\begin{array}{l}\text { Meng } \mathrm{L} \text {, } \\
\text { et al. }\end{array}$ & 2020 & China & $\begin{array}{c}\text { Desafios emergentes } \\
\text { e futuros na prática } \\
\text { odontológica frente o } \\
\text { Covid-19. }\end{array}$ & $\begin{array}{l}\text { Medidas de controle de infecção são } \\
\text { necessárias para impedir a disseminação } \\
\text { do vírus e ajudar a controlar a situaçãoo } \\
\text { epidêmica. Devido às características dos } \\
\text { ambientes odontológicos, o risco de } \\
\text { infecção cruzada pode ser alto entre } \\
\text { pacientes e dentistas. }\end{array}$ & $\begin{array}{l}\text { Para consultórios odontológicos e } \\
\text { hospitais em áreas que são } \\
\text { (potencialmente) afetadas pelo } \\
\text { Covid-19, protocolos rigorosos e } \\
\text { eficazes de controle de infecções } \\
\text { são urgentemente necessários. }\end{array}$ \\
\hline 2 & $\begin{array}{l}\text { Peng } X \text {, } \\
\text { et al. }\end{array}$ & 2020 & China & $\begin{array}{l}\text { Rotas de transmissão } \\
\text { de Covid-19 e } \\
\text { controles na prática } \\
\text { odontológica. }\end{array}$ & $\begin{array}{l}\text { As rotas de transmissão incluem a } \\
\text { transmissão direta (tosse, espirro, } \\
\text { inalação de gotículas), transmissão por } \\
\text { contato (contato com mucosas orais, } \\
\text { nasais e oculares). A via de transmissão } \\
\text { do aerossol e a via fecal-oral afetada } \\
\text { pelo público sugere mais estudos. }\end{array}$ & $\begin{array}{l}\text { Os profissionais da Odontologia } \\
\text { expõem um risco tremendo de } \\
\text { infecção por Covid-19 devido à } \\
\text { comunicação face a face e à } \\
\text { exposição à saliva, sangue e outros } \\
\text { fluidos corporais, e ao manuseio de } \\
\text { instrumentos afiados. Em } \\
\text { contrapartida, estes desempenham } \\
\text { grande papel na prevenção da } \\
\text { transmissão de Covid-19. }\end{array}$ \\
\hline & & & & & & \\
\hline
\end{tabular}




\begin{tabular}{|c|c|c|c|c|c|c|}
\hline 3 & $\begin{array}{c}\mathrm{Xu} \mathrm{H} \text {, et } \\
\text { al. }\end{array}$ & 2020 & China & $\begin{array}{l}\text { Investigar a via } \\
\text { potencial de infecção } \\
\text { por Covid-19 na } \\
\text { mucosa da cavidade } \\
\text { oral (COM). }\end{array}$ & $\begin{array}{l}\text { O ACE2 se expressa na MCO. Este } \\
\text { receptor foi altamente enriquecido em } \\
\text { células epiteliais da língua, indicando que } \\
\text { a MCO pode ser uma via de alto risco } \\
\text { potencial para a infecção do Covid-19. }\end{array}$ & $\begin{array}{c}\text { Esses achados explicaram, de forma } \\
\text { preliminar, o mecanismo básico de } \\
\text { que a CO é um risco potencialmente } \\
\text { alto para a suscetibilidade infecciosa } \\
\text { do Covid-19. }\end{array}$ \\
\hline 4 & $\begin{array}{l}\text { Tang HS, } \\
\text { et al. }\end{array}$ & 2020 & China & $\begin{array}{l}\text { Apresentar um } \\
\text { gerenciamento de } \\
\text { emergência para } \\
\text { prevenção e controle } \\
\text { da infecção por Covid- } \\
19 \text { por profissionais } \\
\text { de odontologia. }\end{array}$ & $\begin{array}{c}\text { Os atendimentos odontológicos } \\
\text { necessitam de gerenciamento de } \\
\text { controle e prevenção para a contenção } \\
\text { efetiva da epidemia. Enfatiza-se a } \\
\text { importância do uso de equipamentos de } \\
\text { proteção individual; higienização; pré- } \\
\text { triagem; além do dever em transmitir aos } \\
\text { pacientes conhecimentos em relação à } \\
\text { prevenção do Covid-19. }\end{array}$ & $\begin{array}{c}\text { Os profissionais de odontologia } \\
\text { devem deter de conhecimento e } \\
\text { requisitos de prevenção e controle } \\
\text { do Covid-19. }\end{array}$ \\
\hline 5 & $\begin{array}{c}\text { Li ZY, } \\
\text { Meng LY. }\end{array}$ & 2020 & China & $\begin{array}{l}\text { Discutir sobre a } \\
\text { prevenção e controle } \\
\text { do 2019-nCov no } \\
\text { diagnóstico e } \\
\text { tratamento oral. }\end{array}$ & $\begin{array}{c}\text { Em decorrência das exposições ao } \\
\text { Covid-19 ocasionadas pelos } \\
\text { procedimentos odontológicos, o risco de } \\
\text { infecção cruzada é elevado. Dessa } \\
\text { forma, medidas de prevenção devem ser } \\
\text { seguidas rigorosamente, considerando o } \\
\text { controle na disseminação de novos } \\
\text { casos. }\end{array}$ & $\begin{array}{l}\text { Os profissionais da Odontologia } \\
\text { precisam conhecer sobre a } \\
\text { prevenção e controle do Covid-19, } \\
\text { gerenciando os pacientes, } \\
\text { realizando os procedimentos de } \\
\text { proteção individual, prevenir } \\
\text { infecções cruzadas, impedindo } \\
\text { dessa forma a disseminação da } \\
\text { epidemia, a segurança do paciente e } \\
\text { a garantia na qualidade dos } \\
\text { atendimentos. }\end{array}$ \\
\hline
\end{tabular}

Fonte: Oliveira JJM, et al., 2020

REAS/EJCH | Vol.Esp.46 | e3487 | DOI: https://doi.org/10.25248/reas.e3487.2020 Página 7 de 12 


\section{DISCUSSÃO}

O Covid-19 apresenta sinais e sintomas semelhantes aos de uma gripe comum e por esta causa se faz necessário realizar testes para comprovar de fato a infecção. Ressalta-se que os sintomas podem variar de leves a graves, o que neste último caso pode acarretar uma pneumonia aguda com alto potencial para gerar falência múltipla dos órgãos (CAMPOS TUÑAS IT, et al., 2020; WANG HJ, et al., 2020).

Os achados de Ruiyun L, et al. (2020), relatam que as infecções não tabuladas, que apresentaram os sintomas aquém do esperado ou assintomáticas, podem ter contribuído para à alta proporção de disseminação do vírus. Portanto, indicaram que $86 \%$ de todas as infecções não foram diagnosticadas e dessas infecções, $79 \%$ tornaram-se fonte de infecção dos casos documentados. O estudo de Li Z e Meng L (2020) relata que existem duas principais vias de transmissão do Coronavírus; através de gotículas respiratórias (tosse, espirro) e contato físico (mãos contaminadas em contato com cavidade nasal, bucal e olhos).

De acordo com Holshue ML, et al. (2020), pesquisadores conseguiram identificar o Covid-19 nas fezes de pacientes da China e Estados Unidos, identificando também a transmissão via fecal-oral. Por meio das principais vias de transmissão do Covid-19, o ambiente odontológico se torna vulnerável, devido ao grande número de aerossóis produzidos pela caneta de alta rotação durante os atendimentos, contendo sangue, saliva e fluidos. O estudo de Tang $\mathrm{H}$, et al. (2020) corrobora esta informação, ao passo que enfatiza a existência de possibilidade da transmissão por aerossol em ambiente fechado por longo tempo, onde as medidas preventivas convencionais se tornam insuficientes mediante a transmissibilidade do vírus em questão.

Em consonância com os achados anteriores, Meng L, et al. (2020), enfatizam que as medidas de biossegurança habitual não são eficazes para impedir a disseminação do Covid-19, principalmente no período de incubação, onde os indivíduos não sabem se estão infectados. Segundo Zhiyong L e Liuyan M (2020), pessoas infectadas, que ainda não apresentam sintomas, se tornam forte fonte de infecção, expondo a equipe odontológica ao risco de infecção ao Covid-19.

No entanto, se faz necessário coletar informações sobre o histórico dos últimos dias do paciente e a condição de saúde geral para nortear o atendimento e/ou levantar suspeita. Os Cirurgiões-Dentistas se tornam vulneráveis aos microrganismos patogênicos, que incluem as bactérias e os vírus que se alojam no trato respiratório e na cavidade bucal.

Devido a prática odontológica ser face a face, a exposição é bem eminente, podendo o contágio acontecer de forma direta ou indireta (Figura 2) (PENG X, et al., 2020; LI Z, MENG L, 2020). 
Figura 2 - Vias de transmissão do COVID-19 em ambiente odontológico.

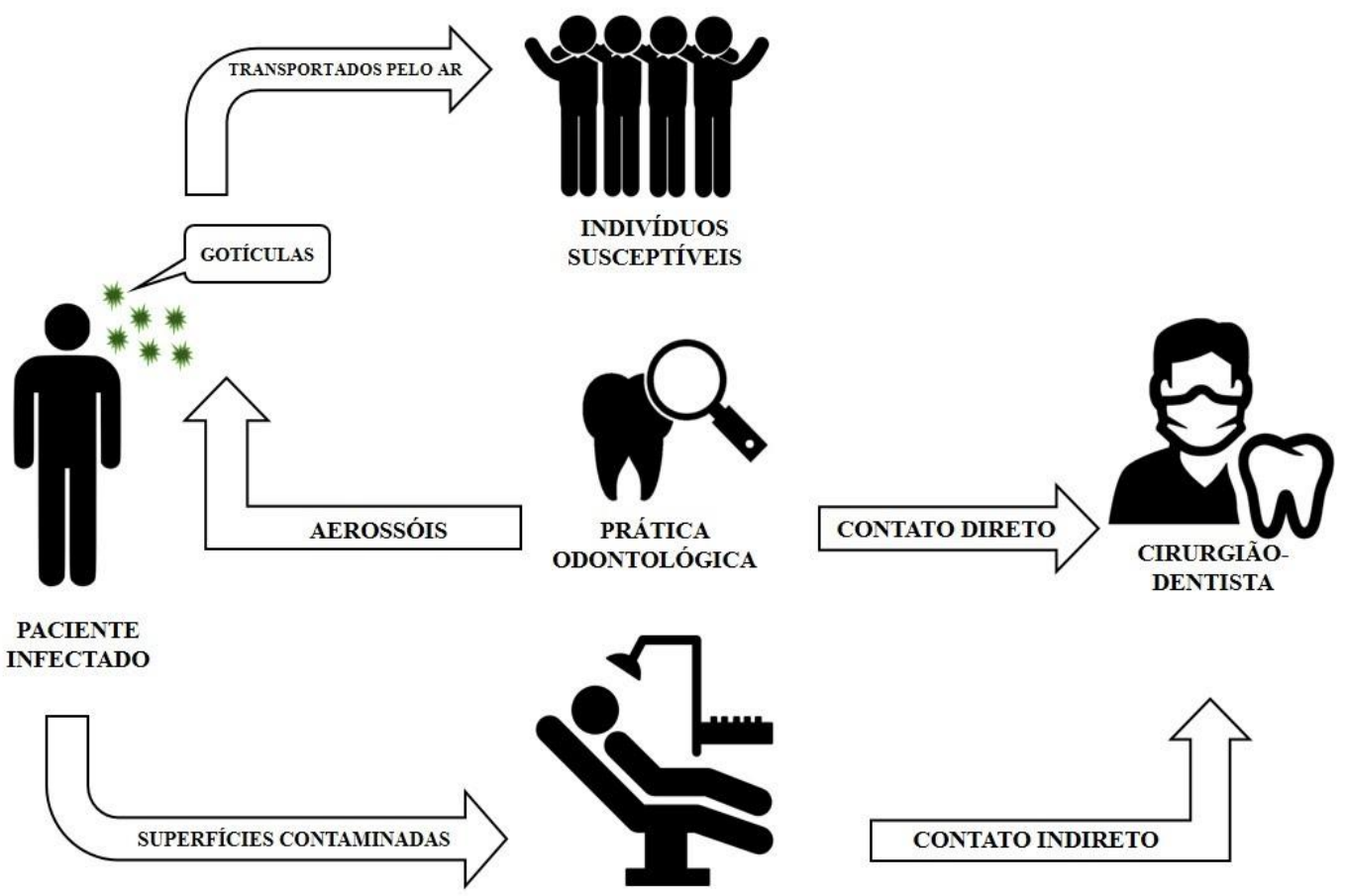

Fonte: Adaptado de Peng X, et al., 2020 e Xu H, et al., 2020.

O estudo realizado por Paz Junior FB, et al. (2019) investigaram as pontas de alta e baixa rotação odontológicas e identificaram a prevalência de duas espécies microbianas: a Candida albicans e Candida krusei, comprovando alta fonte de potencial da infecção cruzada no ambiente odontológico, pois são instrumentos essenciais e bastante utilizados no dia a dia clínico. Então, tanto o Cirurgião-Dentista, quanto os pacientes se tornam indivíduos susceptíveis a contaminação.

No momento atual, os métodos de controle e prevenção da infecção para a população em geral baseiamse em condutas pessoais que minimizem a exposição ao vírus, são elas: uso de máscaras faciais, cobrir tosses e espirros, higienização regular das mãos, resguardar o contato com pessoas contaminadas, evitar levar às mãos ao rosto quando não higienizadas (ADHIKARI S, et al., 2020).

Aos profissionais da Odontologia, as recomendações atuais perpetuam na conscientização da proteção individual, diminuição de procedimentos que possam produzir gotículas e / ou aerossóis, considerando a possível exposição direta do profissional ao vírus (ZHIYOUNG L, LIUYAN M, 2020). Demonstrado no estudo de Liu MH, et al. (2019), foram avaliados 20 dentes permanentes extraídos e perceberam que o tamanho das partículas geradas pela caneta de alta rotação, quando usadas para perfurar os dentes, geralmente são menores que $1 \mu \mathrm{m}$ (micrômetro).

Ainda notaram que, as máscaras N95 e máscaras cirúrgicas são efetivas na filtragem dessas partículas. Contudo, as máscaras cirúrgicas e N95 usadas não oferecem uma eficiência de proteção capaz para impedir a passagem de partículas finas e ultrafinas disseminadas pelas vias aéreas. Portanto, para uma maior eficiência no controle de disseminação de infecções é necessário o uso conjunto com outras barreiras, como as máscaras faciais de plástico.

Como visto portadores assintomáticos do SARS-CoV-2 também são responsáveis pela disseminação e tornam a contenção da pandemia ainda mais difícil, além da transmissão por aerossol, uma vez que o mesmo permanece no meio por horas, e em superfícies por dias. Ademais, o período de latência geralmente varia de 3 a 7 dias, com um máximo de 14 dias, e o vírus também se mostra contagioso neste intervalo de tempo (DOREMALEN N, et al., 2020; ZHIYOUNG L, LIUYAN M, 2020; JIN YH, et al., 2020). 
De acordo com Peng X, et al. (2020), antes de qualquer intervenção odontológica, o profissional deve se atentar para realização de uma anamnese detalhada, embora atendimentos de urgência exijam uma certa agilidade, esta etapa deverá ser respeitada. Nela, algumas informações serão obtidas, como possíveis sintomas febre, alterações respiratórias, gastrointestinais e desconforto geral nos últimos 14 dias. Ademais, deve-se interrogar o paciente quanto a possível exposição ao vírus nos últimos dias, se viajou recentemente para outro país, ou teve contato com pessoas que apresentavam sintomas, e até mesmo diagnóstico confirmado de Covid-19, pois estas informações ajudarão a conduzir com responsabilidade o atendimento. Portanto, os profissionais da Odontologia devem apresentarem-se aptos a identificar casos suspeitos de Covid-19.

No Brasil, o Ministério da Saúde registrou o primeiro caso de transmissão local do Covid-19 em 26/02/2020. Até o presente momento da redação do artigo (28/03/2020 às 13:16h), foram registrados no mundo 621.636 casos de Covid-19, sendo 28.658 mortes. O Brasil possui 93 mortes e 3.477 casos confirmados. No entanto, o estado de São Paulo tem sido considerado o epicentro do surto do Covid-19 no Brasil, registrando atualmente 1.223 casos e 68 óbitos. A taxa de letalidade da doença no país atualmente é de 2,7\% (BRASIL, 2020; ORGANIZAÇÃO MUNDIAL DA SAÚDE, 2020). As gestões governamentais de diversos países adotaram medidas que visam retardar a propagação do vírus e nivelar a demanda aos leitos hospitalares a fim de amparar os pacientes que necessitem de hospitalização e/ou recursos terapêuticos, dentre as estratégias utilizadas estão: o auto-isolamento, quarentena, distanciamento social e contenção social.

As adoções dessas estratégias necessitam da cooperação e da execução de regulamentações a nível local e estadual. Considerando que são condutas desafiadoras frente ao alcance das mídias sociais, é crucial que estas sejam utilizadas de forma consciente, evitando rumores falsos e pânicos quanto a situação vigente (MACINTYRE CR, 2020; BEDFORD J, et al., 2020; WILDER-SMITH A, FREEDMAN DO, 2020).

O Conselho Federal de Odontologia (2020) recomenda que os profissionais utilizem de forma efetiva os equipamentos de proteção individual e realizem uma triagem previamente ao atendimento odontológico para a identificação de possíveis sintomas do Covid-19. Aos serviços públicos de saúde, foi solicitado a suspensão das atividades que não se enquadram nos critérios de urgência ou emergência. $E$ aos estabelecimentos privados solicita-se o máximo de atenção aos protocolos de prevenção. Contudo, sabe-se que as formas de prevenção não estão no total controle do profissional e estes se encontram no mais elevado risco frente ao Covid-19, dessa forma, o isolamento voluntário é a medida mais eficaz durante o surto epidêmico.

Após o atendimento odontológico, o ambiente deve ser limpo e desinfetado. As recomendações indicadas são a utilização de etanol 70\% em superfícies menores, enquanto antissépticos como o hipoclorito de sódio, em concentrações a partir de $0,1 \%$ durante um minuto, tem demonstrado eficácia na eliminação do vírus em superfícies inertes. Entre as superfícies desinfetadas, destaca-se a atenção para as maçanetas, às cadeiras e as mesas, além disso, um ambiente livre de umidade foi recomendado para o controle da difusão do vírus (AMERICAN DENTAL ASSOCIATION, 2020; ORGANIZAÇÃO MUNDIAL DA SAÚDE, 2020; KAMPF G, et al., 2020; IZZETTI R, et al., 2020).

De acordo com os resultados obtidos neste trabalho, observa-se que todos os estudos selecionados para amostra $(n=5)$ foram realizados na China. Isso pode ser justificado devido à China ter sido o primeiro país acometido pelo surto epidêmico do Covid-19, consequentemente esse evento aguçou a comunidade científica a buscar respostas de combate e prevenção desse novo vírus. No entanto, sugere-se que novos estudos sejam realizados em outros países, uma vez que esses dados podem ser utilizados por gestores e profissionais da saúde para elaboração de planos de ação a fim de propagar informações e cuidados essenciais frente à pandemia do Covid-19 através de embasamento científico, tendo em vista que as "Fake News" lançadas em redes sociais têm sido motivo de preocupação.

\section{CONSIDERAÇÕES FINAIS}

As características dos ambientes odontológicos favorecem a infecção cruzada, o que expõe os profissionais e os pacientes a diversos fatores de risco. Mediante o exposto, conclui-se que os profissionais da Odontologia desempenham importante papel no controle e prevenção da transmissão do Covid-19, como 
também são os profissionais de maior risco de vulnerabilidade por causa da contaminação direta através dos aerossóis.

Sendo assim, os cirurgiões-dentistas devem deter de conhecimento e requisitos de prevenção reforçando as medidas de biossegurança através dos equipamentos de proteção individual (EPIs) e, evitar, quando possível, a realização de procedimentos que envolvam a produção de aerossóis e de gotículas, sendo indispensável a observação quanto aos pacientes que apresentarem sinais e sintomas da infecção, que devem ser encaminhados corretamente para o atendimento necessário.

\section{REFERÊNCIAS}

1. ADHIKARI S, et al. Epidemiology, causes, clinical manifestation and diagnosis, prevention and control of coronavirus disease (COVID-19) during the early outbreak period: a scoping review. Infectious Diseases of Poverty, 2020; 9(29):112.

2. AMERICAN DENTAL ASSOCIATION. Coronavirus frequently asked questions. ADA Center for professional Success, 2020.

3. BEDFORD J, et al. COVID-19: towards controlling of a pandemic. The Lancet, 2020; 1-3.

4. BRASIL. Ministério da Saúde. Painel Coronavírus/Brasil. 2020. BRASIL. Ministério da Saúde. Resposta Nacional e internacional de enfrentamento ao novo coronavirus. 2020.

5. CONSELHO FEDERAL DE ODONTOLOGIA. Recomendações AMIB/CFO para enfrentamento da COVID-19 na odontologia, 2020.

6. CORMAN VM, et al. Coronaviruses as the cause of respiratory infections. Internist (Berl), 2019; 60(11):1136-1145.

7. DOREMALEN N, et al. Aerosol and Surface Stability of SARS-COV-2 as Compared with SARS-CoV-1. The New England Journal of Medicine, 2020; 1-3.

8. GUO YR, et al. The origin, transmission and clinical therapies on coronavirus disease 2019 (COVID-19) outbreak - an update on the status. Military Medical Reseach, 2020; 7(11):1-10.

9. HOLSHUE, ML, et al. First Case of 2019 Novel Coronavirus in the United States. New England Journal of Medicine, 2020; 382:929-936.

10. IZZETTI R, et al. Transmissão COVID-19 na prática odontológica: breve revisão das medidas preventivas na Itália. Journal of Dental Research, 2020;1-9.

11. JIN YH, et al. A rapid advice guideline for the diagnosis and treatment of 2019 novel coronavirus (2019-nCoV) infected pneumonia (standard version). Military Medical Research, 2020;7(1):4.

12. KAMPF G, et al. Persistence of coronaviruses on inanimate surfaces and their inactivation with biocidal agents. Jornaul of Hospital Infection. 2020;104(3):246-251.

13. LANA RM, et al. Emergência do novo coronavírus (SARS-CoV-2) e o papel de uma vigilância nacional em saúde oportuna e efetiva. Cadernos de Saúde Pública - Perspectivas, 2020; 36(3).

14. LI Q, et al. Early Transmission Dynamics in Wuhan, China, of Novel Coronavirus-Infected Pneumonia. New England Journal of Medicine, 2020; 1-9.

15. LI Z e MENG L. Emergency management of prevention and control of dental infections in the new coronavirus pneumonia epidemic. Chinese Journal of Stomatology, 2020; 55.

16. LIMA CTK, et al. The emotional impact of Coronavirus 2019-nCoV (new Coronavirus disease). Psychiatry Research, 2020; 112915.

17. MACINTYRE CR. On a knife's edge of a COVID-19 pandemic: is containment still possible? Public Health Reseach Practice, 2020; 30(1):10.

18. MARCEL S, et al. COVID-19 epidemic in Switzerland: on the importance of testing, contact tracing and isolation. Swiss Med Wkly. 2020; 1-3.

19. MENG L, et al. Coronavirus Disease 2019 (COVID-19): Emerging and Future Challenges for Dental and Oral Medicine. Journal of Dental Research, 2020; 1-7.

20. MUNSTER VJ, et al. A Novel Coronavirus Emerging in China - Key Questions for Impact Assessment. New England Journal of Medicine, 2020; 382:692-694.

21. ORGANIZAÇÃO MUNDIAL DA SAÚDE. Doença de coronavírus 2019 (COVID-19). 2020. Relatório de situação-45. Genebra, Suíça: Organização Mundial da Saúde.

22. ORGANIZAÇÃO PAN-AMERICANA DA SAÚDE. Folha informativa - COVID-19 (doença causada pelo novo coronavírus). Brasília, DF, Brasil, 2020.

23. PAZ JUNIOR FB, et al. Prevalência de Candida em equipos das clínicas odontológicas da Faculdade de Odontologia de Pernambuco. CIENTEC- Revista de Ciência, Tecnologia e Humanidades do IFPE, 2018;10(1):65-74. 
24. PEERI NC, et al. The SARS, MERS and novel coronavirus (COVID-19) epidemics, the newest and biggest global health threats: what lessons have we learned?. International Journal of Epidemiology, 2020; 1-10.

25. PENG X, et al. Transmission routes of 2019-nCoV and controls in dental practice. International journal of oral science, 2020; 12(9).

26. RUIYUN L, et al. Substantial undocumented infection facilitates the rapid dissemination of novel coronavirus (SARSCoV2). Science, 2020; $1-9$.

27. STRABELLI TMV e UIP DE. COVID-19 e o Coração. Arquivos Brasileiros de Cardiologia, 2020; n. AHEAD.

28. TANG $\mathrm{H}$, et al. Emergency management of prevention and control of dental infections in the new coronavirus pneumonia epidemic [J / OL]. Chinese Journal of Stomatology, 2020; 55:1-9.

29. TUÑAS ITC, et al. Doença pelo Coronavírus 2019 (COVID-19): Uma abordagem preventiva para Odontologia. Revista Brasileira de Odontologia, Rio de Janeiro, 2020; 77:1-6.

30. VELAVAN TP e MEYER CG. The COVID-19 epidemic. Tropical Medicine International Health, 2020; 25(3):278-280.

31. WANG HJ, et al. Review and Prospect of Pathological Features of Corona Virus Disease. Fa Yi Xue Za Zhi, 2020;36(1):16-20.

32. WILDER-SMITH A e FREEDMAN DO. Isolation, quarantine, social distancing and community containment: pivotal role for old-style public health measures in the novel coronavirus (2019-nCoV) outbreak. J. Travel Med, 2020; 27(2).

33. $\mathrm{XU} \mathrm{H}$, et al. High expression of ACE2 receptor of $2019-\mathrm{nCoV}$ on the epithelial cells of oral mucosa. International Journal of Oral Science, 2020; 12(1):1-5.

34. YANG Y, et al. Facing the COVID-19 outbreak: What should we know and what could we do?. Jornaul of Medical Virology, 2020;1-2. 